\title{
Entrevista a Yosef Grodzinsky
}

(4amila Sevilla ${ }^{1}$

Yosef Grodzinsky dirige el Laboratorio de Neurolingüística del Edmond and Lily Safra Center for Brain Sciences y es profesor en el Departamento de Ciencias Cognitivas de la Universidad Hebrea de Jerusalem. También es profesor invitado en el Instituto de Neurociencia y Medicina en el Centro de Investigación Jülich en Alemania. Durante muchos años fue profesor de lingüística y neurolingüística en la Universidad McGill en Canadá y profesor de neurología en la Universidad de Boston, Estados Unidos. A lo largo de su extensa carrera ha investigado las bases neurales, el procesamiento y la adquisición del conocimiento lingüístico, en particular de la sintaxis y la semántica, así como de la lógica y el razonamiento. Su trabajo ha sido pionero en el estudio de diferentes aspectos formales del lenguaje tanto en individuos sanos como en personas con enfermedades cerebrales. Su investigación actual se enfoca, por un lado, en la evaluación del lenguaje y el tratamiento de la afasia aguda posterior a un accidente cerebrovascular y en neurocirugía; en relación con el procesamiento del lenguaje y su sustento neurobiológico, sus principales intereses se concentran en la base neural de la negación, las habilidades lógicas en la esquizofrenia, la adquisición de la referencia pronominal, el procesamiento de comparativos y la cuantificación en la afasia.

El trabajo de Yosef Grodzinsky ha sido determinante para el campo de la neurolingüística no solo por su contribución a nuestro conocimiento acerca de cómo el lenguaje está representado y es procesado por el cerebro, sino también por su papel decisivo en el desarrollo de la neuropsicología del lenguaje y en el modo de abordar su estudio. Luego del inicio de la revolución cognitiva, el estudio de la afasia, es decir, de las alteraciones del lenguaje debidas a lesiones cerebrales, se convirtió en un terreno de estudio promisorio al calor de la idea de que podía permitir a los investigadores analizar el sistema lingüístico en sus componentes, demostrar la realidad psicológica de procesos y representaciones e identificar su base material en el cerebro. Establecida la neuropsicología cognitiva como disciplina,

1 Agradecemos a Marisol Murujosa y a Camila Stecher, quienes colaboraron en la transcripción de esta conversación. 
se adoptó el supuesto de una congruencia (al menos hasta cierto punto) entre la forma que toman los síntomas de las personas con afasia y los componentes del sistema lingüístico. En este marco, fue Yosef Grodzinsky quien formuló explícitamente la idea de que la gramática, entendida como una descripción con la forma de una teoría, debía no solo ser adquirible sin instrucción por parte de los niños y procesable en el curso normal del desarrollo, sino también compatible con los patrones de deterioro observados en la conducta de las personas con lesiones. Lejos de una desiderata teórica, esta afirmación se convirtió en la plataforma de un detallado programa de investigación que, desde mediados de los años ochenta del siglo veinte, se tradujo en hipótesis audaces y un nutrido conjunto de predicciones específicas y comprobables. Su libro Theoretical perspectives on language deficits, de 1990, expuso en detalle este programa y constituyó, así, un hito en la historia de la investigación del procesamiento lingüístico y sus bases neurales.

Su enorme influencia se plasmó en el tiempo en un volumen notable de investigación empírica detallada y alentó las controversias más estimulantes de la disciplina. Tras cuarenta años de trayectoria, Yosef Grodzinsky continúa extendiendo con rigor y sistematicidad el proyecto de vincular la teoría lingüística y la afasiología para comprender los mecanismos del lenguaje.

\section{¿Cuál dirías que es tu objetivo actual como investigador? No me refiero a tu objetivo personal, que sin duda también nos interesa, sino a aquellos puntos que nuestro campo debería ser capaz de des- cubrir en un plazo razonable dado el estado actual del conocimiento al que hemos llegado.}

Si hay una cosa que todavía me gustaría ver durante mi vida, diría que es un mapa del lenguaje, de las diferentes partes del lenguaje, con mayor detalle que el que hemos visto hasta ahora. Pensémoslo de esta manera. Wernicke fue el primero en tener la noción de un mapa cerebral, porque fue el primero en establecer más de una localización. Él contaba con dos localizaciones, y una vez que tenés dos localizaciones, tenés algo que empieza a parecerse a un mapa, ya no una sola cosa, como tenía Broca, que fue el primero en establecer la asociación precisa entre una función y una región precisa del cerebro. El problema en la psiconeurolingüística actual es que hay toda clase de debates acerca de si ese mapa siquiera existe. Y si existe, cuáles son sus piezas. Lo que yo espero ver es un mapa bastante preciso. Pienso que esto es factible y que nos estamos aproximando. Y además espero que este mapa esté formado por piezas que sean objetos relevantes de la teoría lingüística. Y puedo darte algunos ejemplos. El primer ejemplo es el del movimiento sintáctico. ¿Qué evidencia podría haber? Idealmente, evidencias de distinto tipo. Y es en efecto lo que tenemos. Por un lado, podríamos tener evidencia neuropsicológica, es decir, datos procedentes de las alteraciones del lenguaje causadas por lesiones cerebrales. En lo que llamamos "análisis de déficit", como en la afasia, sabemos que hay una porción de cerebro que falta y como correlato esperamos encontrar indicios de que hay alguna operación que está ausente, en este caso una clase de operación formal. En los primeros tiempos, llamamos a esta idea la "hipótesis de la supresión de la huella". Por otro lado, cabe esperar que 
esta misma operación se manifieste como un incremento de activación de la misma área cerebral en el cerebro sano. De hecho, pienso que hay suficiente cantidad de evidencia respecto del movimiento sintáctico en una parte del área de Broca. Angela Friederici propuso que si miramos el área de Broca (BA 44/45) y la subdividimos teniendo en cuenta criterios citoarquitectónicos, podemos observar que mientras que BA 45 incrementa su activación para el movimiento, BA 44, la parte más posterior, se ocupa de la estructura de frase (Grodzinsky y Friederici 2006). Pienso que es una linda idea. El problema es que todavía no hemos visto pruebas suficientes. Pero es una buena idea, porque de hecho busca obtener un mapa que parcela el conocimiento lingüístico en piezas importantes y trata de localizarlas: podría ser movimiento en el área 45, estructura de frase (o como se dice hoy en día, la operación fusión (merge)) en el área 44, tal vez. Nosotros, en nuestro laboratorio, ahora tenemos nueva evidencia acerca de procesos semánticos, de composición semántica, no del significado de las palabras sino de procesos de composición semántica (Grodzinsky et al. 2020). Hemos llevado adelante este trabajo con un gran grupo de colaboradores, incluso parte de él lo conocés porque lo hicimos con pacientes en Buenos Aires y lo discutimos un poco entonces. La idea básica de lo que observamos es que hay una porción adyacente de corteza que, de hecho, conecta áreas de lenguaje con áreas de la toma de decisiones. Esta porción es llamada "la ínsula anterior" y está involucrada al menos con la negación, y tal vez con otras operaciones lógicas. Entonces, cuando lo pensás, si esto en verdad es así, entonces podemos imaginar, razonablemente, que las representaciones lingüísticas sirven como input a cierta zona lógica que luego produce su output de representaciones lógicas para áreas de razonamiento. Si construyéramos un programa de computación que toma texto y lo entrega a un sistema de razonamiento, esto es exactamente lo que deberíamos pedirle que hiciera: tomar representaciones lingüísticas, traducirlas a un lenguaje estándar como de lógica de predicados y luego mirar estos objetos y sobre la base de estos objetos tomar decisiones. El punto es que, si la evidencia que tenemos es válida, si lo que afirmamos es cierto, entonces estamos ante el comienzo de un mosaico del lenguaje. Vos me preguntabas cuál era mi esperanza. Esta es. Pensá en la corteza visual. Tenemos una descripción muy precisa de V1, V2, V5, y también una idea muy cabal de cómo se organizan funcionalmente los procesos involucrados en la visión que están asentados en esas regiones, una organización que es multicomponencial. Es exactamente lo que pienso que deberíamos lograr respecto del lenguaje.

Me gustaría preguntarte cómo ves hoy la relación entre áreas del saber en la neurolingüística, un campo que se ha vuelto cada vez más interdisciplinario. En los tardíos ochenta y en los noventa del siglo pasado vos defendiste muy fuertemente la idea de que las preguntas de la investigación neurolingüística debían estar estrechamente definidas por descripciones basadas en teoría lingüística. Visto retrospectivamente tu trabajo fue un hito en este sentido. ¿Todavía pensás que la lingüística teórica debe marcar el rumbo de la investigación experimental?

Cuando entré en este campo, prácticamente la única forma de hacer algo en términos de localización era hacer estudios de lesiones. Y, como es sabido, 
el grado de precisión que podemos obtener de la localización anatómica de una función a través de las lesiones no es alto. Además, existen muchos, muchos problemas, que podría enumerar. Uno de los más importantes es, en mi opinión, la posibilidad de recoger grandes cantidades de datos en la etapa aguda. Generalmente no llegamos a los pacientes antes de los tres o cinco meses después del evento que dio lugar a la lesión. Esto es un problema porque no sabemos cuáles fueron los procesos que tuvieron lugar en sus cabezas durante ese tiempo. A veces tenemos algunas pistas, pero en realidad no podemos confiar en eso. Con todo, creo que es un problema q0a suena como una broma. Es como tres, cuatro centímetros entre dos cortes. Realmente no es nada, no era serio. En primer lugar, entonces, hoy en día existen métodos de imagen mucho más potentes, con una resolución muy superior. Esto es fundamental. Estoy hablando de imágenes estructurales. En segundo lugar, tenemos, como decía, una manera de recoger grandes cantidades de datos comportamentales en la etapa aguda. Y, en tercer lugar, ¿quién dice que necesitamos ceñirnos a los estudios de pacientes? Por supuesto que no. Es cierto que los estudios de resonancia magnética funcional (fMRI) tienen todo tipo de problemas. El problema más importante es que, mientras que en los estudios de lesiones se puede ver qué área está involucrada de manera crítica en algún tipo de función (porque la función se ha perdido), en el caso de las imágenes funcionales solo se puede ver un grado relativo de participación. Entonces, cuando los estudios se vuelven más sutiles, las diferencias que encontramos entre las condiciones de prueba y las condiciones de control son muy pequeñas. Exige mucha prudencia y mucho ingenio interpretar estas diferencias.

\section{Entonces, no deberíamos ceñirnos únicamente a ellos, pero tam- poco dirías que llegó la hora de abandonar los estudios basados en lesiones...}

Por supuesto que no. He estado trabajando en imágenes funcionales durante más de 20 años y ni siquiera se me pasa por la cabeza renunciar a los estudios de lesiones. Algunas personas lo hacen, pero creo que es un gran error. Todos esos mapas, dibujados con hermosos colores, pueden resultar muy atractivos, pero siempre hay que recordar que los mapas de imágenes funcionales se basan en la participación relativa de regiones cerebrales en una función, mientras que los estudios de déficit muestran que una determinada región es imprescindible para llevar adelante esa función, aunque no sea tan fácil delimitarla con exactitud. Por eso, lo que necesitamos hoy es recoger información de manera multimodal, con más de un método, y validar por métodos diferentes cada hallazgo obtenido con un método determinado. Esto es lo que llamamos "evidencia convergente". Para retomar el ejemplo sobre el que hablábamos antes: se obtiene una pérdida constante de la operación de movimiento sintáctico cuando se ve afectada el área de Broca - esto es lo que muestran los estudios de lesiones- y eso converge con hallazgos de intensidad de señal elevada en los estudios de resonancia magnética funcional cuando contrastamos condiciones de movimiento en relación con estructuras sin movimiento. Esta es una evidencia convergente y así es cómo, en mi opinión, las cosas deberían funcionar: usar evidencia de distintas modalidades, obtenida mediante distintas técnicas y a través de diferentes tipos de pruebas. Y exigirles que converjan. 


\section{Me gustaría retomar la cuestión de cuál es el papel de la lingüística} teórica en todo esto.

Es, como decía, fundamental. Esto es así porque, como sabés, cuando evaluamos la conducta estamos buscando la estructura, las regularidades de esa conducta. Esto vale para cualquier dominio de indagación de la conducta. En realidad, en la mayoría de estas áreas no hay una teoría que te ofrezca la estructura. Somos muy afortunados de contar con ese tipo de teorías en el dominio visual, en el dominio motor, en menor medida en el mundo de la toma de decisiones y del razonamiento, y somos especialmente afortunados de trabajar en un área en la que en verdad hay mucha teoría. Entonces, por un lado, ¿qué podría ser más natural que usar el vocabulario descriptivo que nos provee nuestra teoría para describir, por ejemplo, la conducta de los pacientes? En lo que hace a mi trabajo actual, destacaría la importancia de incorporar ya no solo conceptos de la teoría lingüística, sino también de la lógica, tanto lógica clásica como no clásica. La lógica proposicional y la lógica predicativa son muy relevantes para la descripción del comportamiento del lenguaje.

Esta es la primera dirección en la que la teoría es relevante, o más bien la relación entre teoría y datos. La otra es, por supuesto, que estos datos, que tienen una orientación más biológica o neurobiológica, deben dar sustento a la teoría. Esto es bastante obvio, no es algo particular de nuestro campo. En nuestro caso, la primera cosa que buscamos es evaluar nuestras teorías lingüísticas pidiéndoles que expliquen los datos neuropsicológicos. Hace muchos años, cuando especifiqué (posiblemente para aclarármelo a mí mismo) lo que debíamos esperar de la teoría lingüística, dije que debía ser compatible con los patrones de deterioro, es decir, con lo que observamos en el comportamiento de las personas con lesiones cerebrales. En su momento, esto fue en los años 1980, mostré algunos de esos patrones, como lo que ocurre en el caso de las oraciones pasivas y cosas de ese tipo. En síntesis, tenemos que exigirle a la teoría que dé cuenta de las distinciones y generalizaciones que encontramos en el desempeño de los pacientes, y también en las señales cerebrales de las personas sanas.

En cuanto a los lingüistas que hacen teoría, ¿creés que comparten este objetivo? ¿Se comprometen con la pretensión de dar cuenta de los datos empíricos?

Sin dudas intentan tener en cuenta los datos empíricos todo el tiempo, aunque quizá no nuestro tipo de datos. Por lo general, el tipo de datos a los que prestan atención provienen del dominio discreto, como la evidencia de experimentos de elección binaria: buenas-malas, aceptables-no aceptables, aciertos-errores, cosas de ese tipo. Y lo especial de nuestros datos es que convertimos los resultados de la experimentación en variables que son continuas, como pueden ser el tiempo, la amplitud o la intensidad de señal, por ejemplo.

Si los lingüistas se comprometen con eso es más bien un problema sociológico; diría que depende: algunos lo hacen, otros no. Si observamos los departamentos de lingüística en los Estados Unidos actualmente, creo que es difícil encontrar un departamento que no tenga al menos un experimentalista. Por 
cierto, la impresión es que en el último tiempo en todo el mundo se contrata a experimentalistas, como debería ser... En el campo de la semántica, por ejemplo, cada vez más investigadores, y en mayor medida, están involucrados en experimentos. Diría entonces que sí hay un compromiso creciente, que podemos tomar estos patrones de contratación como una indicación de que la evidencia experimental se está teniendo en cuenta cada vez más.

Por otro lado, la cuestión es que tenemos una teoría y tenemos datos y rara vez se da el caso de que nuestra teoría se ajuste a todos los datos. Eso es lo normal: si nuestra teoría se ajustara a todos los datos, estaríamos sin trabajo. Volviendo a lo anterior, de hecho, pienso que el diálogo entre teóricos y experimentalistas está aumentando, que hay una nueva generación de criaturas que están bien formadas tanto en teoría como en método experimental, lo cual en mi época era muy inusual: o eras un teórico o eras un experimentalista. Y de repente hay una nueva generación. Esto es, de nuevo, una observación sociológica, y creo que soy más optimista que vos al respecto.

¿Hay un trabajo pedagógico que hacer allí? Quiero decir, como científicos y como docentes, ¿deberíamos intentar persuadir a los estudiantes de lingüística para que vayan en esa dirección?

Claro, creo, por supuesto. Pero pienso que todos nosotros, o la mayoría de la gente que conozco (a menos que estés allí por el fantástico salario que el gobierno argentino te está dando tan amablemente, por supuesto), creemos que lo que hacemos es interesante y que hay buenas razones para que otros hagan lo mismo. Incluso en países que pagan bien a los académicos, creo que muchos de los académicos más prominentes probablemente podrían ganar más dinero en el mundo de la empresa privada. Y sin embargo están allí porque piensan que es interesante y quieren aportar al desarrollo del conocimiento. Eso es parte de la vocación con la que transmitimos a otros, a nuestros estudiantes o a quienes se forman como científicos con nosotros, el modo en el que creemos realmente que deberían hacerse las cosas.

Un tema que tal vez debería enfatizarse es que el lenguaje es menos especial de lo que las personas piensan. Por alguna razón, la gente piensa que el lenguaje es especial y que no puede ser estudiado por las herramientas científicas habituales. Este es uno de los problemas que enfrentamos cuando intentamos decirles a nuestros estudiantes "de acuerdo, usemos el método científico estándar", esto es, racionalizar algo y luego probarlo en el mundo real. Aunque nunca se dio un argumento, dentro de la psicología esta creencia estaba muy extendida y en buena medida creo que por eso el enfoque que se llamó "el método de estudio de caso único", en la psicología cognitiva, fue enormemente exitoso. Una razón de ese éxito se debe a que mostró, allí donde la gente pensaba que el lenguaje era un sistema que no podía estudiarse de la misma manera que otros sistemas en la naturaleza, que era posible abordarlo con el mismo tipo de herramientas científicas. La analogía con el estudio de la estructura del universo, por un lado, y, dentro del cerebro, con el estudio del sistema visual, han sido extremadamente útiles en este sentido. 
Yendo un poco más allá de la cuestión del ajuste entre teoría y datos, y pensando en el modo en el que la teoría se concibe, ¿creés que la teoría lingüística debería tener en cuenta las restricciones psicológicas cuando formula sus descripciones?

Tu pregunta toca a la relación entre el sistema lingüístico y otros sistemas cognitivos, que es compleja. Por ejemplo, cuando te pido que hagas una tarea de comprensión como verificar una oración contra una imagen, tenés que hacer muchas cosas: por un lado, me escuchás, procesás la instrucción en tu cabeza, luego escuchás la oración para compararla con una imagen; por otro lado, la imagen es un objeto visual y hacés todo tipo de cálculos con ese objeto visual; luego te preguntás “¿es o no es?” y finalmente decidís presionar un botón. Se te da una opción binaria y tomás una decisión. Por supuesto, son muchas las cosas que ocurrieron en el medio a las que en principio no tenemos acceso porque no correlacionan con conductas observables. Pero sí tenemos acceso a esas cosas si somos teóricos y experimentadores inteligentes. Una vez que te diste cuenta de que hay toda una serie de procesos en el medio, comenzás a desglosarlos mediante el uso de algunos métodos experimentales con tus modelos teóricos como guía. Entonces, en el caso del estímulo que consiste en una oración y una imagen, podés separar las piezas lingüísticas de aquellas que no lo son, por ejemplo, observando las diferentes áreas del cerebro que cada proceso activa. Podés separarlos por localización. También podrías separarlos mirando las funciones de los tiempos de reacción: un ejemplo de ello se encuentra en un artículo que publicamos en Cognition (Deschamps et al. 2015), que analiza la relación entre el sistema lógico (en este caso, diferentes tipos de cuantificadores) y el sistema numérico. Lo que hicimos allí fue observar la forma de las funciones del tiempo de reacción y ponerlas en relación con las propiedades del estímulo lingüístico, por un lado, y con las propiedades del estímulo visual, por otro lado, y pudimos ver cómo cada una de ellas afecta su tiempo de reacción de una manera muy diferente.

De este modo, separamos los sistemas numéricos y de cuantificación lógica, una distinción que a priori no era evidente, pero que era parte de nuestras hipótesis gracias a la teoría. Entonces, es cierto que solo tenemos acceso a los puntos finales de los procesos, pero si somos suficientemente ingeniosos, tenemos recursos, como las imágenes y otros tipos de señales, para capturar lo que ocurre en medio.

No es muy controvertido decir que la falta de consenso entre las descripciones en lingüística teórica conspiró contra la viabilidad de un programa de investigación empírica dirigido a identificar la base biológica de las representaciones y operaciones lingüísticas. ¿Qué parte de la lógica de dar explicaciones teóricamente informadas puede sobrevivir al dinamismo (o la inestabilidad, si se quiere) de las descripciones teóricas?

Para llevar esto a un ejemplo histórico concreto, en aquel momento planteaste la hipótesis de supresión de la huella (HSH) según la cual una operación (movimiento) -o un elemento representacional resultante de ese movimiento (huellas o cadenas) - se ve afectada en las personas con agramatismo, de modo tal que tienen dificultades 
para interpretar correctamente ciertos tipos de oraciones. ¿Cómo sufrió una hipótesis así el paso de la teoría GB al programa minimalista y después?

¿Qué pasa cuando nos movemos de un marco teórico al siguiente? ¿Las generalizaciones se resienten? Por supuesto que no. Lo que quiero decir es que los hechos siguen siendo los hechos y es el deber de las teorías explicar los hechos. Entonces, el debate entre una teoría A y una teoría B podrá ser el que sea, pero los hechos siguen estando allí, y la motivación para pasar de una a la siguiente puede ser estético, para hacer la teoría elegante o tener menos supuestos, pero también factual. Algunas teorías se vuelven falsas a la luz de la nueva evidencia, son falsadas a medida que surgen nuevos datos. Pero los datos anteriores, si son estables, y siempre que no se haya podido demostrar que son simples artefactos (y pienso que en el caso de la HSH ciertamente no lo son), permanecen y deben ser explicados, de modo tal que el pasaje de una a otra teoría es trivial. En mi caso, en el caso de la $\mathrm{HSH}$, hubo varios intentos de traducir el vocabulario de GB a formulaciones que sonaran más minimalistas. Sin embargo, esos intentos no trajeron una ventaja importante. ¿Cuál hubiera sido una ventaja importante? Pues por supuesto el hecho de la nueva formulación hubiera hecho emerger una nueva predicción. Esto es lo que esperarías; de otro modo, el pasaje es trivial al menos en lo que hace a los hechos que discutimos.

Traigo un par de ejemplos de lo que sucedió en relación con la HSH. Una de las cosas que yo no había pensado personalmente en el momento en el que planteé la HSH fue la cuestión del movimiento de núcleo. En realidad, en aquel entonces no se llamaba "movimiento de núcleo" siquiera. Si no recuerdo mal, la noción de movimiento de núcleo a núcleo proviene de la tesis de Lisa Travis, de 1984. Ella era una estudiante en MIT, que más tarde vino a trabajar a McGill donde fue mi colega, aunque creo que ahora se ha retirado. En su tesis, mirando evidencia de orden de palabras y formación de preguntas, ella propuso restricciones al movimiento de los núcleos. Hasta entonces, la cuestión se había discutido sobre todo en relación con el auxiliar y se planteaba en términos de inversión del auxiliar y el sujeto. Quiero decir que no había una teorización sobre el movimiento de núcleos cuando yo propuse la HSH en 1983. Luego, cuando salió el primer artículo, que creo que fue publicado en el 86 (Grodzinsky 1986), no hice modificaciones teóricas entre la primera presentación y la publicación. Y resultó que había diferencias relevantes entre el movimiento de núcleo y el movimiento de frase. De acuerdo, entonces eso es algo que debe ser explicado. Hay una serie de trabajos, por ejemplo, Grodzinsky y Finkel (1998), en los que evaluamos violaciones gramaticales en personas con afasia y nos dimos cuenta de que había diferencias para detectar violaciones al movimiento de frases y de núcleos. Eso significa que hay que revisar algo: necesitás aplicar restricciones para dar cuenta de esa diferencia de rendimiento, de modo que necesitás entender las propiedades de las huellas del movimiento de núcleos y del movimiento de frases. Yo nunca hice nada en relación con esto, pero es claro que hay diferencias y que por lo tanto hay que hacer esta distinción.

Otro ejemplo que puedo citar de estos movimientos en las descripciones teóricas que motivan nuevas predicciones es el de la elipsis del sintagma 
verbal. Es claro que hay una gran categoría vacía en el lugar de la elipsis de VP. Entonces, ¿cuál es su estatuto dentro de la HSH? Lo que hicimos fue ir a evaluarlo. Es un estudio preliminar, que publicamos hace poco (Grodzinsky, Deschamps y Shapiro 2019) y es realmente limitado porque solo tuvimos acceso a tres pacientes y la variabilidad entre ellos es enorme. Es prematuro sacar conclusiones antes de tener un estudio más amplio, pero todo parece indicar que los pacientes tienen sorprendentemente pocas dificultades con las elipsis de VP.

Justamente la cuestión de la variabilidad (las diferencias en el comportamiento entre pacientes cuyo déficit es clínicamente similar) complicó mucho el trabajo dentro de las investigaciones sobre el procesamiento sintáctico en el cerebro, en particular la interpretación de los datos neuropsicológicos, y generó un debate muy grande. ¿Es posible sortear este problema de la variabilidad en los datos de grupos de pacientes?

Bueno, lo que vos estás diciendo es que el paisaje en el cerebro es muy complejo. Y sí, es muy complejo. La vida es compleja. Lo que yo puedo decirte es que es muy sorprendente para mí que haya gente que ve que su función social en la comunidad científica es decirnos que nos concentremos en el ruido y no en la señal, sin darnos una razón. De nuevo, como vos sabés, estuve involucrado personalmente en debates acerca de la variabilidad. En esta dirección, por ejemplo, Alfonso Caramazza y otras personas que se le unieron sostenían que en la afasia había tanta variabilidad que no podías ver nada a partir de conjuntos de datos. Este debate se terminó en los tempranos 2000. Hay varias razones por las que se agotó el debate, pero una de ellas tiene que ver con que se hablaba de variabilidad sin medirla; hasta que nosotros cuantificamos la variabilidad. Hay un par de trabajos que publicamos con Dan Drai en un volumen especial de Brain and Language dedicado a este debate (2006a y b). Así que medimos la variabilidad y hay muy poco que puedas decir. La cuestión es que nadie niega que haya variabilidad. Pero una de las claves de este tipo de análisis es trabajar a través del ruido y encontrar la señal. Un problema que impregnó el estudio de la afasia es que los métodos analíticos para el análisis de datos eran entonces extremadamente deficientes. Visto retrospectivamente, era patético. Quiero decir, ahora estoy en el centro de la neurociencia, aprendo cosas nuevas todos los días y puedo ver cuán patéticos eran los métodos que todos usamos durante muchos años. Los análisis de varianza y las pruebas T que usábamos, de hecho, no estaban justificados en su mayor parte. El análisis de varianza te obliga a adoptar ciertos supuestos sobre la naturaleza de tus distribuciones (algo que aprendemos en todas las clases de estadística), y me parece que al menos dos de estos supuestos no corresponden nunca en la afasia. Uno es la homogeneidad de la varianza y el otro es que las distribuciones toman la forma de una curva normal, simétrica, en forma de campana. Pero vos sabés tan bien como yo que la probabilidad de obtener este tipo de distribuciones en la conducta de personas con afasia no es alta. Y, sin embargo, durante muchos años, en lugar de decir "bueno, tal vez hay algo mal en nuestros métodos", se dijo que había algo mal con utilizar los datos de los pacientes en sí mismos. "Los grupos de pacientes no 
brindan una imagen uniforme”. ¡No! ¡Los pacientes nos están dando una hermosa imagen! Solo necesitamos tener la lente adecuada. Entonces, algunas personas hicieron grandes carreras gritando y diciendo " $\mathrm{iNooo!}$ Hay demasiada variabilidad", sin pensar realmente en lo que debíamos hacer para entender mejor esos datos y cómo vivir con eso.

Observando tu trabajo de años y escuchando lo que estuvimos charlando hasta aquí, diría que sos optimista respecto de la posibilidad de obtener una imagen clara de la organización funcional y anatómica de la organización del sistema lingüístico, aunque enfrentemos muchas dificultades teóricas y empíricas. Y, sin embargo, hay mucha literatura reciente sobre diferentes aspectos del procesamiento del lenguaje y la lectura que indica que no hay ninguna región del cerebro de la que pueda decirse que interviene en una única función, ni ninguna función que no esté sostenida por una red relativamente distribuida más que por un área anatómica discreta. ¿Este estado de cosas cambió la meta de tratar de correlacionar un tipo particular de computación con un pedazo de tejido que la ejecute?

Si me preguntás cómo tendríamos que lidiar con estos mapas más distribuidos, lo único que puedo responder es que deberíamos trabajar más duro. Pero este asunto de las representaciones distribuidas debe estar respaldado por pruebas. Ahora, está muy claro que los modelos de red y los sistemas de aprendizaje automático son extremadamente útiles para comprender los sistemas neurológicos. No hay duda de eso. Pero eso no significa que no haya pequeños módulos en tu cabeza. Uno de los problemas típicos en la literatura de neuroimagen es que los investigadores que realizan un experimento encuentran seis manchas diferentes en seis partes distintas del cerebro y su primera reacción no es empezar a pensar: ¿hicimos bien el experimento?, ¿analizamos los datos correctamente?, ¿consideramos todas las variables que pudimos? ¡No! En cambio, tienden a pensar que encontraron una nueva red. Entonces, mi enfoque es muy escéptico. Y no creo que la gente mienta; ni siquiera creo que sean malos científicos experimentales. Pero creo que cuando encontrás que algo está por todos lados, primero tenés que a cuestionarte a vos mismo. Primero hay que someternos a un examen muy detallado y solo después podemos hablar de redes. Cuando alguien presenta una nueva red, quiero entender cuáles son las propiedades de esta red, qué restricciones la determinan, por qué debemos asumir que algo está en más de un lugar y así sucesivamente. Por supuesto, las cosas están enormemente interconectadas, pero tenemos que trabajar tomando un camino desde lo simple a lo más complejo, sistemáticamente. Hay que ser muy prudentes y no dejarse llevar por el entusiasmo y afirmar con ligereza que hicimos un gran descubrimiento, porque puede pasarnos que más tarde nos demos cuenta de que era solo un experimento pésimo. Y lo digo no para criticar a otros, sino porque me ha pasado a mí, he sufrido exactamente la misma enfermedad.

Y en este escenario, ¿dónde está hoy la discusión sobre la región de Broca? ¿Qué papel juegan las imágenes funcionales en esto? Vos y tus colegas Angela Friederici y Katrin Amunts han contribuido a identificar subdivisiones funcionalmente relevantes dentro 


\section{de esta región. Parece bien establecido que se trata de un área multifuncional. ¿Sigue pareciendo una etiqueta útil a pesar de esta multifuncionalidad?}

Por supuesto, no se puede negar que hay multifuncionalidad en áreas del cerebro. Lo que puedo negar definitivamente es que todas las funciones que se le han atribuido a la región de Broca estén realmente ahí. Permitime darte un ejemplo: hay un estudio del año 2001, de un amigo mío, Ferdinand Binkofski (Binkofski et al. 2001), que ha sido citado cientos de veces hasta ahora, realmente muchas veces. Primero que nada, tengo que aclarar que los métodos de imágenes eran entonces todavía muy primitivos, con una resolución realmente baja. Ahora, cuando mirás el estudio, lo que hicieron fue pedirle a la gente que imaginara diferentes tipos de movimientos: movimientos simples y complejos. Y mostraron que activaban el área de Broca, porque encontraron mayor activación de una subregión particular para los movimientos complejos que para los simples. Pero esperá un momento: el hecho de que hayas dado a los sujetos tus instrucciones antes de la prueba no significa que no se las hayan repetido a sí mismos mientras la estaban haciendo. De hecho, es muy probable que haya sido así. Y cuando mirás las instrucciones que les dieron, no te sorprende que las instrucciones verbales para imaginar un movimiento simple fueran mucho más simples que las instrucciones verbales que para imaginar movimientos complejos. Realmente no había que ser un genio para pensar en eso, pero nunca lo pensaron. Y no lo pensaron no porque fueran tontos (son mis amigos), sino porque entre la enorme cantidad de cosas que buscamos controlar cuando hacemos manipulaciones experimentales aparecen muchísimos atajos que a veces no calculamos de antemano. Y tampoco estoy diciendo que tenga la respuesta correcta para esto. Lo traigo solo como ejemplo de que muchas veces intentamos inventar la rueda donde en realidad no debería inventarse. Porque en este ejemplo en particular no se hizo nada para separar las instrucciones y sus repeticiones mientras los participantes llevaban a cabo el acto de imaginar. Ahora hace algún tiempo que no lo hago porque me cansé, pero lo cierto es que pasé mucho tiempo despejando la basura del camino y llamando a la prudencia ante este tipo de hallazgos y afirmaciones. Y es lo que hay que hacer. En síntesis, no niego que haya múltiples funciones en muchas regiones del cerebro y Broca entre ellas, pero seamos un poco más cuidadosos antes de sacar conclusiones.

\section{Volviendo a las dificultades empíricas, ¿cuál es el papel de las dife- rencias microanatómicas entre sujetos?}

Esa es una pregunta muy difícil. No creo que estemos en condiciones de estudiar las diferencias microanatómicas entre sujetos, y te diré por qué. El acceso que tenemos actualmente a la microanatomía es solo a través de cadáveres. En este momento no tenemos acceso a través de imágenes ni en el nivel citoarquitectónico, ni en el nivel histológico. La forma en que localizamos cosas es configurando el mapa anatómico a través de personas muertas que donaron su cerebro. Este es el tipo de trabajo más actual de Amunts. Y luego tratamos de conectarlo con cualquier dato que obtengamos de personas que están vivas. En este punto, no sé si podemos estudiar este tipo de variabilidad de manera seria. Quiero decir que se ha intentado hacerlo, pero no he visto nada que me haya parecido particularmente esclarecedor hasta el momento. 
¿Creés que es posible separar los efectos de la memoria de trabajo y los efectos del movimiento sintáctico, si es que son cosas distintas? Creo que sí, de hecho, esto es algo que Andrea Santi hizo en mi laboratorio hace unos diez años. Hubo una serie de estudios que se publicaron entre 2007 y 2008 (Santi y Grodzinsky 2007, Grodzinsky y Santi 2008) que mostraban exactamente eso. En una serie de experimentos de resonancia magnética funcional manipulamos paramétricamente la demanda en dos tipos de dependencias, una con movimiento y otra sin movimiento, y logramos mostrar una activación selectiva en cierta región específica en el área de Broca para el movimiento, manteniendo constante la demanda de memoria de trabajo. De este modo logramos separar los efectos de uno y otra. Este fue el estudio de movimiento versus ligamiento que hicimos por primera vez con afásicos. Es un hermoso estudio, que fue parte de su tesis.

¿Pensás que las teorías basadas en rasgos (como la propuesta de Rizzi o Grillo) pueden ayudar a elucidar las dificultades en el procesamiento de oraciones en personas con agramatismo? Creo que ofrecen una forma interesante de integrar los efectos de la disponibilidad de recursos y los que provienen de la dificultad representacional intrínseca. En primer lugar, de todas maneras, me gustaría preguntarte si este punto de vista difiere del tuyo en aspectos que considerás significativos.

Nino (Grillo) tomó la teoría de los rasgos de Rizzi y reformuló la $\mathrm{HSH}$ (Grillo 2008, 2009). Eso está perfectamente bien. Quiero decir que lo que hizo Nino fue lo correcto, pero - aunque es posible que me haya perdido algo- no he visto que a partir de esta reformulación hayan surgido nuevas predicciones que alteren significativamente el paisaje de lo que sabíamos. Creo que todavía falta extender el trabajo sobre su perspectiva de modo que aparezcan predicciones contrastantes, algo que realmente nos diga que se requiere una teoría basada en rasgos para la descripción del déficit. Espero que lo haga. Nino es un tipo muy inteligente y creo que lo que hizo fue genial. Simplemente habría que empujar sus ideas hasta el final para hacer predicciones.

Hay un trabajo atractivo más o menos reciente que muestra cómo la construcción de estructura de frase modula la actividad del hemisferio izquierdo del cerebro usando registros intracraneanos (Nelson et al. 2017). Parece un intento de avanzar sobre terreno sólido (nadie se atrevería a cuestionar la existencia de constituyentes inmediatos, digamos), pero al mismo tiempo es metodológicamente sofisticado y en cierto sentido difícil de interpretar para los lingüistas. ¿Creés que es una forma novedosa de demostrar, como argumentan los autores, la realidad psicológica de las operaciones lingüísticas básicas como la "fusión" (merge)?

Para ser honesto, no veo nada extraordinariamente nuevo allí, aparte de algunos trucos tecnológicos muy interesantes. Quiero decir, hay una gran cantidad de trabajo desde la década de 1960 que muestra que construís árboles en tu cabeza. Podemos llamarlo "fusión" o de alguna otra manera. Si quieren llamarlo "fusión", llamémoslo "fusión", está bien. Pero no significa que este estudio nos traiga algo realmente nuevo en términos de evidencia. 
Sabemos que se pueden rastrear procesos de estructura de frase tanto en el tiempo como con otros métodos. De hecho, hay un estudio muy elegante de Ding et al. que ellos mismos citan, publicado en Nature Neuroscience en 2015, que rastrea la construcción de distintas estructuras jerárquicas lingüísticas abstractas mediante MEG. Hay mucho trabajo de este tipo. Esto que muestran aquí es algo emocionante porque se hace intraoperatoriamente, pero, con el debido respeto, en cuanto a hallazgos empíricos relevantes, no veo nada especial. Y en cuanto a la significación teórica, tampoco creo que haya aquí un argumento para una definición particular de la operación "fusión" sobre otra, como cuando Chomsky introduce la noción "fusión" (merge) con intención de establecer una diferencia con las reglas de estructura de frase, como un nuevo concepto. Creo que estarás completamente de acuerdo conmigo en esto.

Para terminar, hablemos un poco de tu trabajo actual. Desde hace algún tiempo venís trabajando en semántica y en particular en el procesamiento de la negación y los cuantificadores. ¿Cuáles son tus descubrimientos más importantes en esta área y cómo se vinculan estos resultados a tu programa de investigación más general?

Si tengo que elegir un hallazgo, diría que es que aislamos la ubicación de la negación lógica, la separamos del lenguaje. Encontramos la negación lógica fuera del lenguaje en la parte anterior de la ínsula. Este es un trabajo que venimos haciendo en conjunto entre mi laboratorio y el laboratorio de Katrine Amunts. Sobre la base de nuestro cluster funcional, Katrine mapeó la microanatomía de la región (en las áreas 44 y 45 de Brodmann en el hemisferio izquierdo, esto es el área de Broca) y el grado de coincidencia entre ambos es asombroso.

Entonces, si estoy en lo cierto, si nosotros tenemos razón, podemos ver que anatómicamente la posición de este grupo funcional se encuentra entre el lenguaje y las áreas anteriores, que son áreas de toma de decisiones, como el cíngulo anterior. Y lo que espero es que estemos viendo un puente entre el lenguaje y la toma de decisiones a través de un sistema lógico. Esta es mi expectativa. Si hay algo nuevo, creo que esto es lo más emocionante.

Suena verdaderamente ambicioso.

Bueno, ¿qué sería de nosotros si no tuviéramos ambiciones? 


\section{Q Bibliografía}

" Binkofski, Ferdinand, Katrin Amunts, Klaus Stephan, Stefan Posse, Thorsten Schormann, Hans-Joachim Freund, Karl Zilles y Rüdiger Seitz. 2001. "Broca's region subserves imagery of motion: A combined cytoarchitectonic and fMRI study". Human brain mapping 11: $273-85$.

》Deschamps, Isabelle, Galit Agmon, Yonatan Loewenstein y Yosef Grodzinsky. 2015. "The processing of polar quantifiers, and numerosity perception". Cognition 143: 115-128.

» Ding, Nai, Lucia Melloni, Hang Zhang, Xing Tian y David Poeppel. 2015. "Cortical Tracking of Hierarchical Linguistic Structures in Connected Speech". Nature neuroscience 19: 158-164.

"Dan Drai y Yosef Grodzinsky. 2006a. "A new empirical angle on the variability debate: Quantitative neurosyntactic analyses of a large data set from Broca's Aphasia”. Brain $\&$ Language 96: 117-128.

》Dan Drai y Yosef Grodzinsky. 2006b. "The variability debate: More statistics, more linguistics”. Brain \& Language 96: 157-170.

" Grillo, Nino. 2008. Generalized Minimality: Syntactic Underspecification in Broca's aphasia. LOT Dissertations Series, vol. 186. Utrecht: LOT Publications.

» Grillo, Nino. 2009. "Generalized Minimality: Feature impoverishment and comprehension deficits in agrammatism". Lingua 119, 10: 1426-1443. https://doi.org/doi:10.1016/j. lingua.2008.04.003

"Grodzinsky, Yosef. 1986. "Language deficits and the theory of syntax". Brain and Language 27, 1: 135-159.

" Grodzinsky, Yosef y Lisa Finkel. 1998. "The neurology of empty categories aphasics' failure to detect ungrammaticality". Journal of cognitive neuroscience 10, 2: 281-292.

" Grodzinsky, Yosef y Angela Friederici. 2006. “Neuroimaging of syntax and syntactic processing”. Current Opinion in Neurobiology 16, 2: 240-246.

" Grodzinsky, Yosef y Andrea Santi. 2008. “The battle for Broca's region”. Trends in Cognitive Sciences 12, 12: 474-480.

" Grodzinsky, Yosef, Isabelle Deschamps y Lewis Shapiro. 2019. "Patients with Broca's aphasia and Young Children can reconstruct elided VPs". En The Oxford Book Handbook of Ellipsis, editado por Jeroen van Craenenbroecky Tanja Temmerman. New York: Oxford University Press.

»Grodzinsky, Yosef, Isabelle Deschamps, Peter Pieperhoff, Francesca lannilli, Galit Agmon, Yonatan Loewenstein y Katrin Amunts. 2020. "Logical negation mapped onto the brain". Brain Structure and Function 225, 1: 19-31.

" Grodzinsky, Yosef, Virginia Jaichenco, Isabelle Deschamps, María Elina Sánchez, Martin Fuchs, Peter Pieperhoff, Yonatan Loewenstein y Katrin Amunts. 2020. "Negation and the brain: experiments in health and in focal brain disease, and their theoretical implications". En Oxford Handbook of Negation, editado por Viviane Deprez y María Teresa Espinal. NY: Oxford University Press.

» Nelson, Matthew J., Imen El Karoui, Kristof Giber, Xiaofang Yang, Laurent Cohen, Hilda Koopman, Sydney S. Cash, Lionel Naccache, John T. Hale, Christophe Pallier y Stanislas Dehaene. 2017. "Neurophysiological dynamics of phrase-structure building during sen- 
tence processing". Proceedings of the National Academy of Sciences of the United States of America 114, 18: E3669-E3678. https://doi.org/10.1073/pnas.1701590114

"Santi, Andrea y Yosef Grodzinsky. 2007. "Working memory and syntax interact in Broca's area". Neurolmage 37: 8-17. 